\title{
NEW DEVELOPMENTS IN TEXTILE WARPING: PART I- REVIEW OF LITERATURE
}

\author{
ASHWIN THAKKAR ${ }^{1} \&$ SOMESHWAR BHATTACHARYA ${ }^{2}$ \\ ${ }^{\text {I}}$ Professor, Head, Textile Technology Department, L. D. College of Engineering, Ahmedabad, India \\ ${ }^{2}$ Professor, Dean, Faculty of Technology \& Engineering, M.S. University of Baroda, Vadodara, India
}

\begin{abstract}
Woven system is still highly preferred for formation of fabrics, mainly for apparel purposes. Warping is an inevitable process for preparing warp for weaving process. Mainly, there are two systems of warping viz. direct and indirect (or Sectional). Both systems have their own application areas and are used for making different varieties of fabrics. Still, not much work has been done to combine both applications into one system, and there by prepare beams containing all one colored or patterned ends. In this paper, a review has been carried out to analyze pros and cons of both systems. The paper also contains a review about various attempts, which have been made to unify both the systems into one.

KEYWORDS: Warping, Direct, Indirect, Creel, Beaming, Beam, Bobbin, Head Stock \& Loom
\end{abstract}

Received: Jul 04, 2017; Accepted: Jul 24, 2017; Published: Jul 31, 2017; Paper Id.: IJTFTAUG20175

\section{INTRODUCTION}

Weaving is one of three major methods of producing fabric. Woven fabrics are highly preferred for many of the apparel and home textile products and to some extent for technical textile products. Production of woven fabrics involves winding, warping, drawing-in and weaving processes apart from yarn spinning process. Yarn is packed in an individual form up to winding stage, which means that the wound bobbin contains one yarn of very large length. This bobbin is useful for variety of end users, like as weft for shuttle and shuttle less loom, for knitting process etc.

Warping has been defined as "Warping comprises winding parts of the warp yarns, normally from bobbins, on a warping beam, whereby sequential parts are wound next to each other until the full weaving width is covered. The warping beam is then normally in a next step of warp preparation used for beaming." Whereas, beaming is defined as "Beaming comprises winding the full width of the warp yarns in a single winding operation on the weaving beam (i.e. the beam which is to be placed on the loom). The warp yarns can be wound from a creel or a warping beam". (CPC, n.d.)

The final woven fabric has several thousands of warp threads woven with weft yarn. The weft yarn is supplied directly on the loom. So, producing a suitable system of supplying required number of warp threads wound for sufficient length on a suitable package, necessary to carry out the weaving process continuously. This task is done in two steps namely, warping and sizing. The objective of the warping process is to convert the single yarn packages (last product of the winding process) into multi thread beam. The beam produced at the warping stage will have the several hundreds of warp yarns wound in the form of parallel sheet. The number of threads 
wound at a time will be decided by the creel used.

There are two most popular methods of carrying out the warping process as below: (Lord et.al, 1982, Gandhi, 2012, Dorgham, 2013).

- $\quad$ Direct warping

- Sectional warping

\section{Direct Warping}

Direct warping is used mainly for producing beams containing mono colored warp threads. The machine comprises of two main elements namely, the creel and the headstock. The process involves use of a creel, where the given numbers of warp bobbins are mounted and from each bobbin, the warp thread is taken forward up to head stock and then, it is wound on a beam named warper's beam. Due to limitations of accommodating a very large creel, the number of bobbins which can be taken will be limited to 1000 - 1200 only (Adanur, 2001). This number is smaller than the requirement of several thousands of warp threads in the final woven fabric. So, there is one more process after direct warping for agglomerating few of the warper's beams to get the final beam suitable for use on the loom. This final beam is named weaver's beam. The process can be carried out through sizing operation, where, a coating of size film is applied on the final warp sheet. Alternatively, the beams can be combined by a simple re-beaming process if the sizing is not required to be done.

The process of direct warping is simple, but has limitation that only single colored warp can be used. Also, the length of yarn to be wound per beam should be sufficiently large, as the machine is running at speeds of more than 600 $\mathrm{mpm}$. So, direct warping is not a preferred choice for small length production. Warper's beams have the full width required finally, but the number of threads is only few hundred as mentioned earlier. So, length of yarn wound on warper's beam can be very large. As many beams are to be combined at a later stage, it is very difficult to process warp yarns having patterns. Matching of the patterns will become highly complicated issue and in complex patterns will be impossible. On the other hand, the production of the system is very high so suitable and preferred for producing simple varieties at mass scale.

\section{Sectional Warping}

There are three main parts of this system: the creel, head stock and the beaming system. The creel is more or less same as that used in direct warping. Yarn is taken from creel and is brought up to the head stock in the form of a small width section. As the winding of the yarn takes place section by section (Majumdar, 2014), there is need to support the yarn sheet particularly when the flanges are not there. The head stock consists mainly of a one side conical shaped large drum. The angle of the cone can be fixed or variable depending on the manufacturer. Today most of the machines are sold with fixed cone angle. The yarn is mounted on the flat part of the conical drum. The width occupied by the yarn on drum will be exactly the width the same yarn will occupy on weaver's beam. As the drum starts rotating, the section of the yarn is wound on the drum and at the same time, there is provision to traverse section of the yarn in such a way that shifting of the section occurs towards the raised conical part of the drum. After completion of winding of the required length, the yarn section is cut and the whole section is brought back to a point where, second section will start. In similar way, the winding of all the sections, as per requirement, will be carried out. So, in the end the entire yarn length is now stored on the drum. Now, transferring the yarn stored on the drum to beam is carried out through a separate beaming device - an integral part of 
the machine. So, process occurs as a two-step process.

In this system, all the ends required finally will be wound on the beam, so there is no need to agglomerate separate beams like direct warping. As all ends are to be accommodated on the drum, it is possible to use the system for warp having multi colored patterns. Again, as all ends have been transferred on the drum and later on, on the beam, there is possibility of using the beam directly on the loom if sizing is not required to be done. Also, the process will be highly preferred if small length of warp is to be processed.

On the other hand, the system has few problems like only small length of yarn can be accommodated on the drum. So the final beam may not have very large length of warp or many weavers' beams cannot be produced like direct warping. This system may not be suitable for mass production of simple varieties. This particular fact sometimes works in the benefit of weavers if the lot size is small. Cost of the machine is also comparatively very high and is justified, only if there is sufficient requirement of suitable varieties. Lastly, the machine is more complex in nature and fine-tuned calculations are required to be done to get the required characteristics of weaver's beam.

Both the systems of warping have been used over the decades. Manufacturers find their own solution in selecting either or both systems of warping. As written in previous section, it is evident that one is required to select the warping system based on the final fabric to be produced and that there is no single system which provides solution for all kinds of fabric production. There have been many attempts in earlier time, wherein, researchers have tried to find the solution to the problem but none have gained commercial success.

\section{LITERATURE REVIEW}

As mentioned earlier not much work has been reported in the books or journals regarding the attempts made at unifying two systems of warping. Most of the work is reported in to patents.

In 1935, a patent was registered by Loncteaux H.J, Norton J.F and Griffis L.W. from USA. (Loncteaux, et.al., 1935) The patent is mainly an early version of sectional warping with claims of increased speed, better control over threads and improved braking mechanism. Also claimed was, the dividing plates with a small number of threads in a particular section. Possibility of adjusting the width between plates was affected by means of mechanical adjustments.

An important patent was filed in 1961, by Harris from Great Britain (Harris, 1960). The invention is about the modified design of the flanges and means of fixing flange onto barrel. The basic idea is to avoid the damage that occurs to yarns when flanges run on threads made on to the barrel surface. Due to this sometimes scratches, cuts etc. happen on barrel surface and cause damage to some of the delicate yarns. Also the lock nuts or mechanism used to fix flanges on barrel cause damage. Both the problems have been taken care of by means of providing new design which has teeth made on inside of flanges and barrel.

Another important US patent was registered by Erwin P. for Sulzer Brothers limited in 1978 (Erwin, 1978). As per Erwin, the multi-component warp beam is made of at least two telescoping parts with a clamping means pressing the parts together radially from within the area of overlap. As shown in Fig 1, the clamping provided includes a wedge shaped plate pressed by means of a partially threaded spindle. This concept of beam is an extension of another patent filed by Scholze G. et.al. (Scholze, 1974) in 1974. 


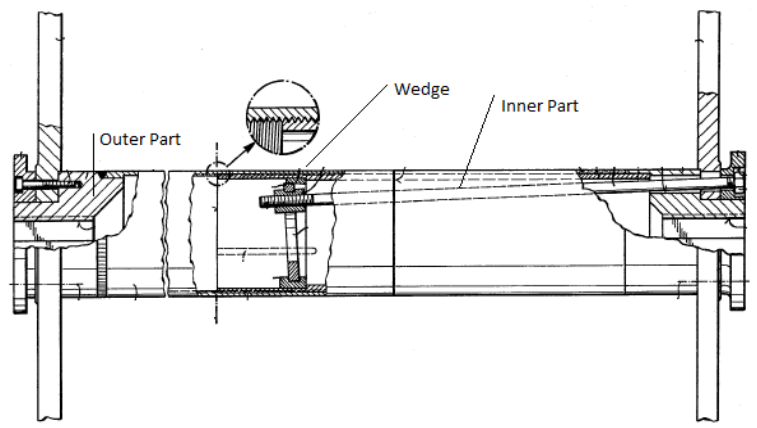

Figure 1: Multi-Component Warp Beam (Erwin, 1978)

Later on in 2003, a US patent was registered by Colson W.B. et.al, regarding a totally new concept of organizing the creel to be used for warping. As shown in fig. 2, the creel is arranged in a shape of circle. As per the discussion in the patent, this helps in maintaining an equal distance to be travelled by all threads while reaching the head stock and so, the force required to pull the yarn will be same for all threads(Colson, et.al., 2003). A turn table that supports two or more beams is provided to facilitate the rapid switching of beams once one beam is full.

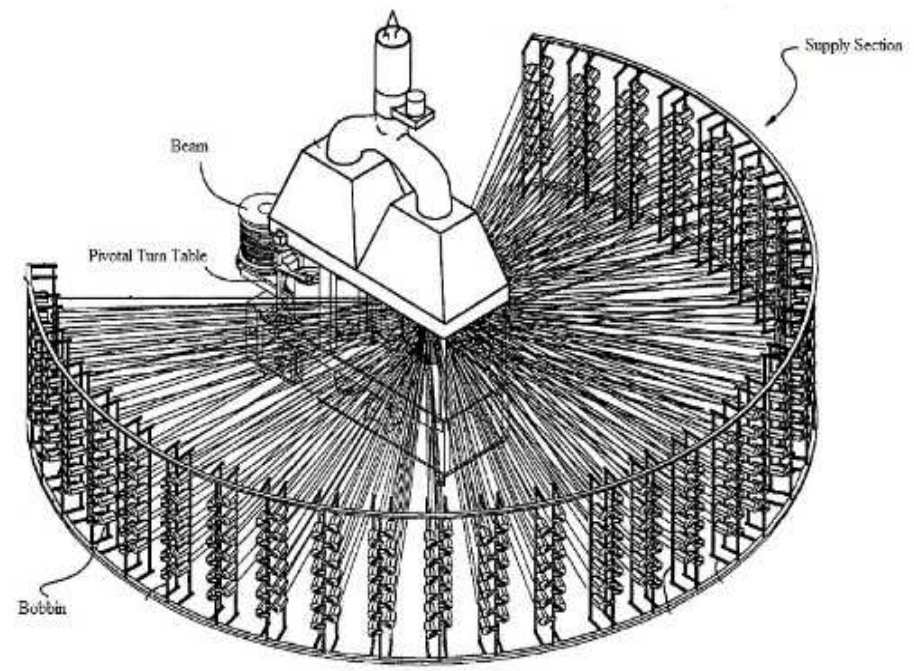

Figure 2: Beam Winding Apparatus (Colson, 2003)

The invention by Agnihotri is about a design of an apparatus for warping high twist fine count yarn on a direct warper over a narrow width and then dyeing the same on a slasher dyeing machine (Agnihotri, 2008). Use of narrow width beam permits better control over thread, especially when higher tensions are to be applied. The pressure roller is also adjusted accordingly.

\section{CONCLUSIONS}

Many similar attempts have been carried out to make minor or major modifications in the current systems of direct and sectional warping machines. Most of the attempts were aimed at increasing productivity, providing ease of operation to workers, reducing the time required for creeling, providing novel means of inserting lease etc. Not many attempts have been made to provide a single system for the varieties of yarn i.e. mono colored and patterned. The work, which will be presented here, provides an attempt to unify both the systems in such a way that, only one system will be used to warp any type of yarn. 


\section{REFERENCES}

1. CPC-Cooperative Patent Classification, D02H - Warping, Beaming or Leasing, (n.d.). Available at: http://www.cooperativepatentclassification.org/cpc/definition/D/definition-D02H.pdf. accessed on 18.08.2015

2. Lord, P.R. \& Mohamed, M.H.(1982). Weaving: Conversion of Yarn to Fabric. Durham, England: Merrow Publishing Co. $L t d$.

3. Gandhi, K. L. (2012). Woven textiles Principles, developments and applications. Cambridge: Woodhead Publishing Limited in association with The Textile Institute.

4. Dorgham, M.E. (2013). Warping Parameters Influence on Warp Yarns Properties: Part 1: Warping Speed and Warp Yarn Tension. Journal of Textile Science and Engineering, 3(2).

5. Adanur, S. (2001). Handbook of Weaving. Boca Raton, USA: Taylor \& Francis (CRC Press).

6. Dr.Majumdar, A. (2014). Fabric Manufacture I. (MHRD, GOI) Available at: http://nptel.ac.in/courses/116102005/ Accessed on 31.08.2015

7. Loncteaux, H. J., Norton, J.F. \& Griffis L.W. (1935). USPatent No. 2017008.

8. Harris, S.A. (1960). GB Patent 838364.

9. Erwin, P. (1978). US Patent No. 4083513.

10. Scholze, G. (1974). German Patent DE19702046995.

11. Colson, W.B., Fogarty, D.M., \& Hartman, D.P. (2003). US Patent No. 20030233744.

12. Agnihotri, K. (2008). Patent No. WO2008044241. 
